\title{
Integration of reproductive health services for men in health and family welfare centers in Bangladesh
}

\author{
Ubaidur Rob \\ Population Council \\ Sharif M.I. Hossain \\ Population Council \\ M.E. Khan \\ Population Council \\ Ahmed Al-Sabir \\ Mohammed Ahsanul Alam
}

Follow this and additional works at: https://knowledgecommons.popcouncil.org/departments_sbsr-rh

Part of the Family, Life Course, and Society Commons, International Public Health Commons, and the Maternal and Child Health Commons

How does access to this work benefit you? Let us know!

\section{Recommended Citation}

Rob, Ubaidur, Sharif M.I. Hossain, M.E. Khan, Ahmed Al-Sabir, and Mohammed Ahsanul Alam. 2004.

"Integration of reproductive health services for men in health and family welfare centers in Bangladesh," FRONTIERS Final Report. Washington, DC: Population Council. 


\section{Integration of Reproductive Health Services \\ for Men in Health and \\ Family Welfare Centers \\ In Bangladesh}

September 2004

National Institution for

Population Research and

Training, Dhaka

Ahmed Al-Sabir

Mohammed Ahsanul Alam
Population Council, Dhaka Sharif Mohammed Ismail Hossain Ubaidur Rob

ME Khan

This study was funded by the UNITED STATES AGENCY FOR INTERNATIONAL DEVELOPMENT (USAID) under the terms of Cooperative Agreement Number HRN-A-00-9800012-00, and Population Council Subagreement A100.46A and In-house Project 580013037. The opinions expressed herein are those of the authors and do not necessarily reflect the views of USAID. 


\section{EXECUTIVE SUMMARY}

Over the last 30 years, the Bangladesh national family planning program has mainly concentrated its promotional efforts on encouraging women to adopt family planning. Most of the grassroots workers who are responsible for delivering family planning services are women. While the government policy has been effective in influencing women to accept contraceptive methods, men's role in family planning has been completely neglected. Similarly, male reproductive health services are rarely available at Health and Family Welfare Centres (HFWCs), the lowest level of rural clinic for providing health and family planning services. This project's aim was to integrate male reproductive health services within the existing government female-focused health care delivery system.

The National Institution for Population Research and Training (NIPORT), in collaboration with the Directorate of Family Planning and the Population Council, implemented the study over a period of two years. It used a quasi-experimental non-equivalent control group design, with eight HFWCs as intervention sites and four HFWCs as control sites. Service provider interviews, focus group discussions, inventory surveys, male and female exit client interviews, and client registers were used to collect the data. Interventions included training regarding reproductive tract infections (RTIs) and sexually transmitted infections (STIs) for service providers, awareness raising about male RTIs and STIs, group discussions, behavior change communication materials (BCC) materials, and RTI and STI services using the syndromic approach.

The interventions resulted in a substantial increase in male clients (ages 15 years and above) in the experimental clinics from 131 clients to 337 clients per clinic per month. Analysis revealed, however, that nearly all of the male clients seeking services from HFWCs came for the treatment of general health problems. Only a small number of male RTI and STI clients sought services from the clinics. The number of RTI and STI clients increased from a monthly average of less than one client per clinic prior to the intervention to more than five during the intervention period. There was also an unexpected substantial rise in the number of female clients (15 years and above) including those seeking treatment for RTIs and STIs. The rise in the number of both male and female clients increased use of the HFWC and helped reduce the cost of treating each client. The most common symptom of RTIs and STIs for which men sought services was urethral discharge. Because of limitations in the study, an increase in condom use could not be assessed.

The study findings confirmed the following hypotheses:

- Service providers' technical knowledge about male reproductive health problems and syndromic management of RTIs and STIs increased as a result of training.

- If male reproductive health services are included within the female focused HFWCs, and men know about them, then they will use the services.

- Inclusion of reproductive health services for men at HFWCs will not have an adverse effect upon the number of female clients who seek treatment from the same clinics. 
- Interventions will lead to an increase in the number of male clients with RTIs and STIs at experimental clinics.

- There is no need to alter the working hours of HFWCs to accommodate male clients, particularly those seeking treatment for RTIs or STIs.

The study concluded that reproductive health services for men could easily be integrated into the HFWCs without affecting the clinics' focus on serving women and children. Men were found to be willing to use the existing services within the routine service hours of the clinics. Women did not show any apprehension in using the health services because of the presence of male clients. Service providers, however, need practical training to diagnose and treat RTI and STI cases. To meet the requirements of the additional clients, extra medicines should be supplied. Finally, the rise in the total number of male and female clients at HFWCs will lead to more effective use of resources with increased use of health facilities and decreased cost of treatment per patient. 


\section{CONTENTS}

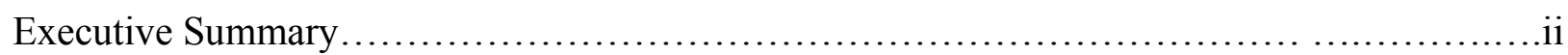

List of tables and figures....................................................................

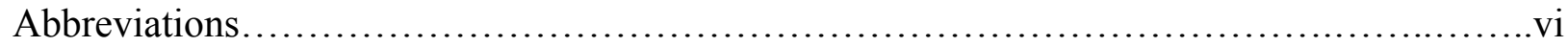

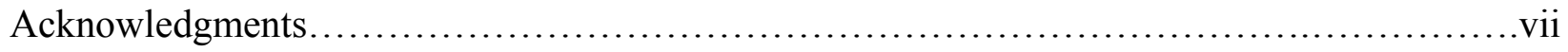

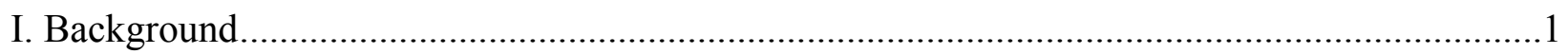

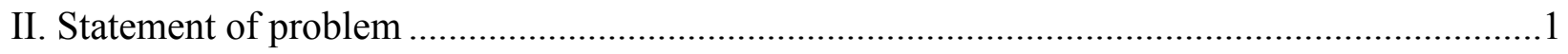

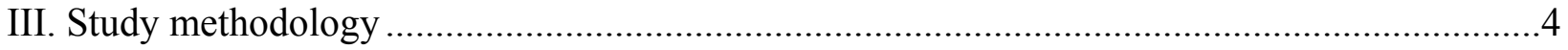

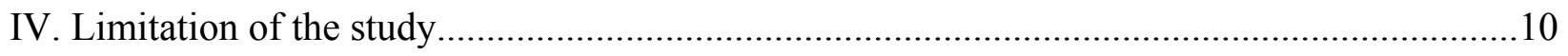

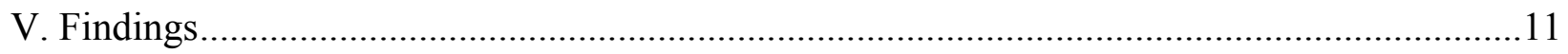

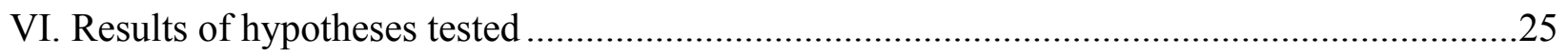

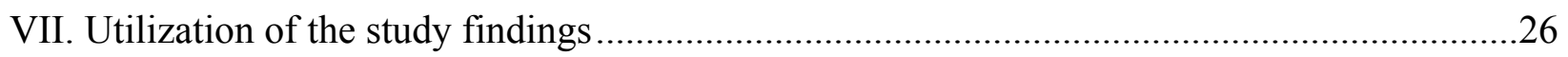

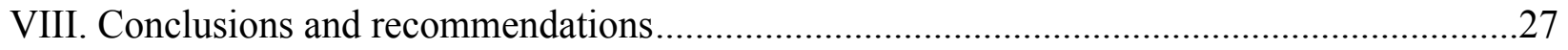

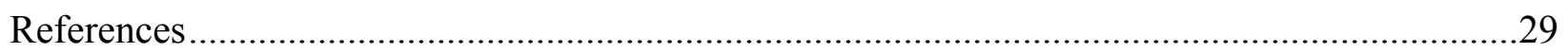

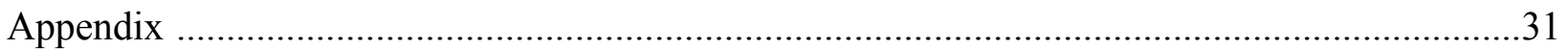




\section{LIST OF TABLES AND FIGURES}

Table 1. Number of service providers and field workers interviewed before and after the intervention by experimental and control areas

Table 2. Distribution of service providers who can name specific STIs

Table 3. Number of service providers and field workers who know the signs and symptoms of male RTIs and STIs, pre- and post-intervention

Table 4. Number of service providers who know about the transmission and prevention of HIV/AIDS

Table 5. Percent distribution of service providers who feel comfortable discussing sex and sexuality with clients, pre- and post-intervention

Table 6. Distribution of all clients including those receiving RTI and STI services, by age and sex

Table 7. Distribution of STI and RTI clients treated before and after the intervention

Table 8. Background characteristics of male and female clients

Table 9. Percent distribution of clients by reason for current visit to HFWC

Table 10. Percent distribution of male clients who experienced symptoms of RTIs and STIs in the previous three months and their treatment-seeking behavior

Table 11. Percent distribution of opinions of male and female clients about the service delivery

Table 12. Summary of the results of hypotheses tested

Figure 1. Monthly average number of male clients (ages 15 and above) in HFWCs excluding RTI and STI cases

Figure 2. Monthly average number of female clients (ages 15 and above), excluding RTI and STI cases

Figure 3. Monthly average number of male and female RTI and STI clients (ages 15 and above)

Figure 4. Source of information about RTI and STI services

Box 1. Decisions taken in the first review workshop

Box 2. Observations made in the second review workshop 


\section{ABBREVIATIONS}

$\begin{array}{ll}\text { BCC } & \text { Behavior Change Communication } \\ \text { BDHS } & \text { Bangladesh Demographic and Health Survey } \\ \text { CPS } & \text { Contraceptive Prevalence Survey } \\ \text { ESP } & \text { Essential Service Package } \\ \text { FPI } & \text { Family Planning Inspector } \\ \text { FWA } & \text { Family Welfare Assistant } \\ \text { FWV } & \text { Family Welfare Visitor } \\ \text { HFWC } & \text { Health and Family Welfare Center } \\ \text { HA } & \text { Health Assistant } \\ \text { HIV/AIDS } & \text { Human Immunodeficiency Virus/Acquired Immune Deficiency Syndrome } \\ \text { IEC } & \text { Information, Education, and Communication } \\ \text { MCH } & \text { Maternal and Child Health } \\ \text { NIPORT } & \text { National Institution for Population Research and Training } \\ \text { NSV } & \text { No-Scalpel Vasectomy } \\ \text { OR } & \text { Operations Research } \\ \text { RTI } & \text { Reproductive Tract Infection } \\ \text { SACMO } & \text { Sub-assistant Community Medical Officer } \\ \text { STI } & \text { Sexually Transmitted Infection } \\ \text { UHC } & \text { Upazila Health Complex }\end{array}$




\section{ACKNOWLEDGMENTS}

The authors wish to thank the FRONTIERS Program of the Population Council for their technical and financial support in conducting this operations research. Special thanks are due to Director General, the National Institution for Population Research and Training (NIPORT) for his comments on earlier drafts of this report.

The authors are grateful to the Director General, Directorate of Family Planning; Line Director, Directorate of Family Planning; Civil Surgeon and Deputy Director of Dhaka, Khulna, Rajshahi, and Sylhet districts; Upazila Health and Family Planning Officer and Upazila Family Planning Officer of Iswarganj, Dumuria, Birol and Bianibazar upazilas; Family Welfare Visitor, Sub-Assistant Community Medical Officer, and Medical Assistant of Maijbag, Sohagi, Khornia, Atlia, Mongalpur, Forokkabad, Alinagar, and Lawtha unions; Principal of FWVTI Khulna, Dinajpur, and Sylhet; and Training Officer of RTC Iswarganj for their valuable contributions to implementing the intervention.

Special thanks are also given to Dr. Jahiruddin Ahmed, the then Director (MCH), Directorate of Family Planning, for his invaluable contribution in all the steps of this study. 


\section{BACKGROUND}

The overall objective of the study was to increase men's access to and acceptance of reproductive health services at Health and Family Welfare Centers (HFWCs) in Bangladesh. The study was conducted in collaboration with the National Institute of Population Research and Training (NIPORT), the Directorate of Family Planning, and the Population Council. NIPORT is a national research and training under the Ministry of Health and Family Welfare. The Directorate of Family Planning provides reproductive health services including family planning at the union level (the lowest administrative unit, covering a population of 30,000 to 50,000 ) through its 3,700 HFWCs. These centers offer curative and preventive services to mothers and children. Each HFWC is staffed by a Family Welfare Visitor (FWV) and a Sub-Assistant Community Medical Officer (SACMO). They are supported by five to seven Family Welfare Assistants (FWAs). FWVs are traditionally women who have received 18 months of basic training in reproductive and child health care and provide family planning and maternal and child health $(\mathrm{MCH})$ services. SACMOs, on the other hand, are predominately men who have three years of basic training in reproductive health, child health care, and basic medical services. They provide general health care, child health care, and treatment for minor ailments to both male and female clients.

The study activities began in November 2000 and were completed in December 2002. The study was carried out in the four major divisions of Bangladesh: Dhaka, Khulna, Rajshahi, and Sylhet. The interventions were tested in twelve government health facilities. The primary intervention groups in the study were men of reproductive age and grassroots-level service providers. NIPORT and the Directorate of Family Planning implemented the study with technical assistance from the Population Council.

\section{STATEMENT OF PROBLEM}

Since the mid-1970s, the Bangladesh national family planning program primarily focused on motivating women to use modern contraceptive methods and encouraging them to seek services from clinics. In addition, female field workers were recruited to deliver contraceptive methods at homes. The program design facilitated women's access to information and medical care through clinics and home visits. In the process, however, medical needs of males were marginalized. Men now generally seek services from pharmacies, private practitioners, and district hospitals. Studies showed that men often ignore preventive steps and postpone seeking medical care for chronic health conditions. In cases of acute episodes of illnesses, they often resort to self-medication (Piet-Pelon and Rob 1997; Piet-Pelon, Rob and Khan 2000; Population Council 1996a).

Studies also revealed that men do suffer from various reproductive health problems (Piet-Pelon and Rob 1997; Population Council 1996a; Hussain et al. 1996). Nevertheless, they do not use the services provided by HFWCs. Even for general health care, the majority of men do not seek services from HFWCs. One of the possible reasons may be the general perception that HFWC services are only for women and children, not for men. To address this issue, the Population Council, in collaboration with NIPORT and the Directorate of Family Planning, attempted to reach men through existing government staff at HFWCs in 1997. A small-scale study conducted in one HFWC yielded promising results, but the findings were inconclusive for making policy recommendations. The study showed that no-scalpel vasectomy (NSV) and condom use increased considerably in the intervention area. FWAs have also 
shown potential to reach males with BCC materials (Directorate of Family Planning, NIPORT, and Population Council 1998).

A review of the literature revealed lack of knowledge among men and women about STIs, including HIV/AIDS. According to the 2000 Bangladesh Demographic and Health Survey (BDHS), only 31 percent of ever-married women and 50 percent of currently married men have heard of HIV/AIDS (NIPORT, Mitra and Associates, and ORC Macro 2001). Only 24 percent of the women and 22 percent of the men said that they had talked with their spouses about HIV/AIDS. Furthermore, 89 percent of the women and 81 percent of the men did not know of any STIs other than HIV/AIDS. Although about 6 percent of the married women knew about STIs, they were not aware of any signs and symptoms of STIs. Nine percent of men and 2 percent of women were able to cite two or more signs and symptoms. More than 5 percent of the men reported that they had had an STI in the last year (NIPORT, Mitra and Associates, and ORC Macro 2001).

The reported statistics on awareness of STIs contradict the reality that STIs and RTIs are highly prevalent in the general population of Bangladesh. About 56 percent of women in rural Bangladesh suffer from RTIs; among this group, 21 percent have STIs (Hussain et al. 1996). The high incidence of STIs among women is an indirect indicator of the high prevalence of these diseases among men (Population Council 1996b; Wasserheit et al. 1989; Hussain et al. 1996). A number of factors have contributed to the spread of STIs among men and women. To begin with, health and family planning programs have failed to address gender relations between men and women and to emphasize their shared responsibilities in ensuring sexual health and well-being (Asian-Pacific Resource and Research Centre for Women 1996). Moreover, women are generally ignorant about the signs and symptoms of male STIs, even though many men are engaged in risky sexual behaviors (Ashraf et al. 1999).

The negative attitude and inefficiency of service providers contribute to the prevalence of STIs (Khan et al. 1996). Contacting male partners is not a priority for female field workers during their routine home visits. The majority of them consider it inappropriate to talk to men even about family planning issues. They feel particularly uncomfortable demonstrating and explaining male contraceptive methods. Family Planning Inspectors (FPIs), who are primarily responsible for contacting and providing men with correct information about male methods and for encouraging them to accept such methods, have not been fulfilling their assigned responsibilities. Perhaps their negligence is a result of the tradition of training and the job orientation for field workers, which has focused on women (Khan et al. 1996). As a result, they have not been advised or educated about the importance of male involvement or encouraged by their supervisors to contact men (Population Council 1997).

During recent decades, the extensive development of behavioral change communication (BCC) materials on family planning, including condoms and vasectomy, has taken place in Bangladesh. Very few of these materials, however, focus on men's responsibilities in family planning and the reproductive health of couples. Research findings indicate that BCC materials could play a major role in motivating men to assume responsibility in family planning (Ashraf et al. 1999). Results from a case study in the Philippines confirmed that these materials help encourage and sustain male involvement in reproductive health (David 1996). The author suggested that programs, policies, and legislation should encourage male involvement in the reproductive and sexual 
health of the family. Findings from Zimbabwe indicated that men can be influenced by family planning messages if appealing and appropriate communication channels are used (i.e., incorporation of images of virility into the messages) (Kim et al. 1996). Similar efforts to educate men about the importance of their role in reproductive health have not been made in Bangladesh (Donahoe 1996). Thus, existing educational approaches and program activities should be reviewed and modified, so that both partners can receive services. To ensure effective male participation in couples' reproductive health, it is necessary to provide men with adequate information about reproductive and sexual health through appropriately designed and culturally sensitive BCC materials (Kim et al. 1996).

While training plays a major role in improving the knowledge and skills of service providers, it is often neglected in the public sector. Service providers at the grassroots level lack practical experience in identifying cases of RTIs and STIs mainly because the basic training course about RTIs and STIs does not include clinical training. Because of this lack of knowledge, training, and skills, service providers are unable to treat cases of RTIs and STIs even when they use the syndromic approach (Khan et al. 1996; Donahoe 1996). Therefore, it is essential to provide practical training and demonstrations to providers in identifying and treating cases of RTIs and STIs

Like women, men have reproductive health concerns change over time. The absence of adequate reproductive health education combined with the proliferation of traditional but ineffective healing practices have led to men's lack of awareness of the signs and symptoms of RTIs and STIs, as well as the modes of transmission and means of prevention. All these issues lead men to disregard or not use available health services (Ashraf et. al 1999). Appropriate program efforts are needed to educate men about reproductive and sexual health, healthy practices, and the services available at health facilities including HFWCs.

The health-seeking behavior of men in Bangladesh needs to be improved. Most often men procure medical services from unqualified medical practitioners and pharmacists, or they rely on medicating themselves. Also, men are embarrassed to obtain services for RTIs and STIs from institutional facilities (Donahoe 1996; Ashraf et al. 1999). However, there is growing realization that unless services reach men, efforts to improve women's reproductive health will also have limited impact (Directorate of Family Planning, NIPORT, and Population Council 1998).

The present scenario calls for designing appropriate interventions and action plans for effectively involving men, sustaining their participation in the reproductive health of couples, and encouraging them to accept services from existing government health facilities (Directorate of Family Planning, NIPORT, and Population Council 1998; Ashraf et al. 1999). The current structure of the female-focused health service delivery system in Bangladesh offers little scope for dealing with the reproductive health problems of men. The challenge is to find ways to respect men's needs using existing resources without adversely affecting women's access to, and use of, services. The present operations research (OR) project builds on the experiences of a Population Council supported pilot OR study that was carried out under an Asia and Near East Operations Research and Technical Assistance Project to enhance the use of HFWCs to provide male reproductive health services (Directorate of Family Planning, NIPORT, and Population Council 1998). 


\section{STUDY METHODOLOGY}

\section{Objectives}

The overall objective of the study was to increase men's access to, and acceptance of, reproductive and sexual health services at HFWCs. Specific objectives consisted of the following:

- Increase access to reproductive health services for men at HFWCs with an emphasis on RTIs and STIs and sexual health counseling.

- Modify existing BCC materials to increase men's acceptance of male family planning methods and reproductive health services, and their understanding of reproductive health responsibilities.

- Encourage men to obtain and use male family planning methods, including NSV, from the HFWC.

- Introduce RTI and STI services for men at HFWCs using the syndromic approach at HFWCs.

- Assess the management, technical, and financial implications of integrating male reproductive health services into the existing service delivery system.

\section{Hypotheses}

The following hypotheses were tested in the study:

- The training will augment service providers' technical knowledge about male reproductive health problems and management of RTIs and STIs using the syndromic approach.

- If services for men are made available at HFWCs and if they are publicized in the community, then men will use the services.

- The interventions to increase the use of HFWCs by men will not have an adverse effect upon the number of female clients seeking treatment from the same clinics.

- The provision of male reproductive and sexual health services at HFWCs will increase the use of the facilities by male clients, including treatment for STIs.

- BCC activities, combined with counseling men at clinics and in the community, will lead to increased use of condoms and NSVs.

- There is no need to alter the working hours and timing of HFWCs to accommodate male clients.

\section{Study Design}

In the present study, a quasi-experimental non-equivalent control group design was used with eight HFWCs selected as intervention sites and four chosen as control sites. The experimental and control clinics were selected from the four largest administrative divisions of the country (two experimental and one control HFWC from each division). A three-member team visited the selected upazilas (health districts) and identified the HFWCs for the study. The HFWCs were chosen purposively after considering criteria such as adequate staff, proximity to urban areas, 
and established infrastructure. From the adjacent upazila, a third HFWC with comparable characteristics was identified and selected as a control site. A management committee was formed at the beginning of the project to monitor project activities. The committee comprised members from NIPORT, the Directorate of Family Planning, and the Population Council.

\section{Dependent Variables}

The dependent variables considered for this study include: 1) a rise in the number of male clients seeking services from HFWCs; 2) an increase in the number of men who obtained RTI and STI services from the health facility; 3 ) an increase in service provider's technical knowledge to identify and treat RTI and STI cases; and 4) a rise in the number of clients at HFWCs who used family planning services for men.

\section{Data Collection Techniques}

The study was conducted in three phases: situation analysis, implementation of interventions, and impact assessment. The situation analysis took six months; the intervention lasted 12 months; and the impact assessment took another six months to complete. The situation analysis and impact evaluation were conducted through an inventory survey, analysis of service statistics (client registers), exit interviews, focus group discussions, and pre- and post-intervention tests of the service providers on knowledge and management of RTI and STI cases. These data were collected in both the experimental and control areas. In addition, two workshops were conducted with the program managers and service providers to review the project activities and seek their suggestions.

\section{Inventory Surveys}

Inventory surveys were conducted in the eight experimental and four control HFWCs both before and after the intervention. Inventory surveys were conducted to assess the readiness of the health facilities to provide RTI and STI services. Data collection included information on the availability of medicine for RTIs and STIs and infection prevention equipment such as a Sims speculum, cotton, and antiseptic agents.

\section{Service Statistics}

Monthly service statistics were collected from all of the study clinics to estimate the total number of clients who used any health services, the number of RTI and STI clients examined, the number of referrals made, the number of clients who obtained condoms from the clinics, the number of condoms distributed by the field workers, and the number of sessions on partner management. The figures were obtained from the service registers maintained at the study centers and covered the periods before and after the intervention.

\section{Client Exit Interview}

Client exit interviews were conducted with 286 men (220 in the experimental sites and 66 in the control site) and 300 women (175 and 125, respectively) during the intervention. The client exit 
interview sought to assess the quality of services provided at the centers, the type of counseling provided by the service providers, clients' views about the policy of serving both men and women at the same clinic, and feedback about clients' experiences at the centers. The interviews also assessed clients' reproductive health knowledge and practices, the purpose of their visit at the HFWC, and whether or not they had experienced RTIs or STIs in the last three months. All of the 300 female exit client interviews were conducted during the last three months of the intervention. Interviews with male clients were conducted throughout the intervention to provide continuous evaluation of the service delivery. Ninety-six of the interviews with male clients took place during the first nine months of the intervention; the remaining 190 took place during the last three months.

\section{Focus Group Discussion}

Focus group discussions were conducted before and after the intervention to collect information on community perceptions about the health centers, reasons why men do not seek treatment from HFWCs, and suggestions about how to respond to male clients' needs, particularly RTIs and STIs, from the existing health service delivery system. Seven focus group discussions (five in the experimental and two in the control areas) were conducted with men before the intervention, and 16 (eight each in the experimental and control areas) were conducted after the intervention period. The informants for these discussions were community leaders, such as teachers, businessmen, religious leaders, and local political representatives, as well as male members of the community, who included agricultural and general laborers. Four focus groups each in the experimental and control areas were conducted with adolescents following the intervention. The post-intervention focus group discussions assessed participants' perceptions about the recent inclusion of male STI services in the HFWCs, the reaction of men and women to these changes, the quality of services provided from the HFWC, and suggestions for improvement.

\section{Interview of Service Providers}

Pre- and post-intervention interviews were conducted with 127 service providers and 163 field workers. Out of the 127 pre-intervention interviews, 29 were with the service providers (19 in experimental clinics and 10 in the control sites), and the rest (98) with the field workers (75 and 23, respectively). Similarly, among the 163 post-intervention interviews, 33 (26 and 7, respectively) were with the service providers and the remaining 130 (86 and 44, respectively) were with the field workers. Service providers were asked about their knowledge of RTIs and STIs, how much information they retained after 12 months of training about the signs and symptoms of RTIs and STIs among male and female clients, and their practices regarding partner management and sexual health counseling. Subjects were also queried about the supply of medicine and their suggestions about how to provide services to enhance men's access to and use of reproductive health services. The same questionnaire was used both in the pre- and postintervention surveys except that in the post-intervention survey, new questions were added about the provision of male RTI and STI services. 


\section{Review Workshops}

Two review workshops were conducted with program managers and service providers. The workshops were conducted during the fifth and $12^{\text {th }}$ months of the intervention period. The objectives of the first workshop were to review the project activities, share experiences, assess performance, analyze difficulties, and discuss emerging issues. All program managers from the respective Upazila Health Complexes (UHC) and senior officials from NIPORT and the Population Council participated in this first workshop.

The objectives of the second review workshop were to share both positive and negative experiences from the field, provide suggestions for improving the program, and to develop recommendations for extending project activities in other areas. Program managers and one provider from each of the experimental UHCs attended the second workshop, along with senior project officials from NIPORT, the Directorate of Family Planning, and the Population Council.

\section{Data Processing and Analysis}

The principal procedure for analyzing the quantitative data was to provide descriptive statistics on each variable collected during the study and to compare the findings from experimental and control groups, both before and after the intervention. The significance of the differences in proportion was tested using the "Z" test, while the "t" test was used to analyze differences in the means. Qualitative data analysis provided in-depth understanding of community perceptions of the project and about the influence of different variables in the experimental and control areas. Direct quotes have been used whenever possible to strengthen and complement the observations made from the quantitative data.

\section{Interventions}

Four types of interventions were introduced in the experimental clinics:

- Theoretical and practical training of service providers about RTIs and STIs and their management using the syndromic approach for men.

- Inclusion of RTI and STI services in the HFWCs.

- Promotion of awareness about male RTIs and STIs and availability of reproductive health services for men at HFWCs through group discussions with adult and adolescent men and development and distribution of BCC materials.

- Mobilization of additional drug supplies from existing government resources.

\section{Workshops with Program Managers}

A training manual for service providers was developed in concert with program managers and NIPORT training staff, who discussed and finalized the training material at a three-day workshop. The training manual covered important theoretical aspects of the Essential Services Package (ESP), safe motherhood, family planning, gender issues, syndromic management of RTIs and STIs, couples counseling, sexual health counseling, and men's role in couple's reproductive health care. To ensure proper implementation of the project, researchers also held 
two orientation workshops in the experimental areas to orient district- and upazila- level managers about the study's objectives, design, and proposed activities.

\section{Training of Service Providers}

Ninety-four Family Welfare Visitors, Sub-Assistant Community Medical Officers, Family Welfare Assistants, and Health Assistants from the experimental area attended a five-day training course taught by district- and upazila- level officials. The course included three days of theoretical and two days of practical training on RTIs and STIs. The theoretical training mainly concentrated on the essential services package, safe motherhood, family planning, gender issues, syndromic management of RTIs and STIs, health counseling for couples, sexual health counseling, and the role men can play in couples' reproductive health care. Practical training was given on the diagnosis and management of RTI and STI cases. Lectures, demonstrations, role plays, and group discussions were used to conduct the training.

The medical officer and staff from the Health and Family Planning Office, who were also the trainers for the theoretical portion of the training, conducted the practical training at the UHC. Because the number of clients with STIs at UHC was small, practical training at the first stage was not satisfactory. Hence, after the first review meeting, it was decided that service providers should be given practical training again. Accordingly, they attended a special five-day training course organized at the Skin and Venereal Disease Department of the Medical College Hospital. This training substantially improved their ability to diagnose and treat cases of RTIs and STIs.

\section{Awareness Promotion}

In the eight experimental areas, different approaches were used to make community members aware of the availability of services for male clients at HFWC and to encourage them to use the services. These approaches included group discussions, distribution of behavior change communication (BCC) materials, and public announcements.

\section{Group Discussions}

During the first eight months of the interventions, six to eight group discussions were organized in each union. Each union is administratively divided into three wards, with each ward consisting of three to five villages. Thus, an average of two group discussions were held in each ward each month. A total of 436 group discussions were organized in eight unions during the first eight months of the intervention. Fieldworkers organized meetings with about 20 to 30 participants each, including local community leaders, religious leaders, adult males, and male adolescents. FPIs and SACMOs conducted group discussions on RTIs and STIs, male responsibility in couples' reproductive health, and the availability of RTI and STI services for men at HFWCs. 


\section{Distribution of BCC Materials}

A total of seven BCC materials were developed for distribution by modifying existing materials. Five posters on male reproductive health were designed to convey: 1) signs and symptoms of RTIs and STIs in men and women; 2) consequences and treatment of STIs; 3) availability of male RTI and STI services from the HFWC; 4) condom use; and 5) no-scalpel vasectomy. Posters were displayed and leaflets and brochures were distributed at each experimental HFWC and at popular meeting places for men. Among the materials, a special leaflet and a brochure were designed to explain the signs and symptoms of RTIs and STIs in male and female clients and their sequelae, and how men can play a vital role in improving a couple's reproductive health. A signboard indicating that male reproductive health services were available was also placed in front of each clinic. Two flip charts developed by the Population Council, illustrating the signs and symptoms of RTIs and STIs, were provided to the service providers in each experimental HFWC to use during service delivery and client counseling. More than 30,000 BCC materials were distributed during the first and third quarters of the intervention period.

\section{Public Announcements}

In four experimental areas, health assistants rented loudspeakers for one day, rode through their respective unions in cycle rickshaws, and broadcasted messages about the availability of reproductive health services for men at the HFWCs. This type of promotion was conducted only once during the study and resulted in a sudden increase of clients at the HFWC. However, service providers could not keep up with client loads and the demand for additional medicine. Hence, this approach for informing community members was discontinued.

\section{Provision of RTIs and STls and Other Reproductive Health Services}

At the experimental HFWCs, RTI and STI clients (both men and women) were treated by FWVs and SACMOs. They counseled clients, and depending on the availability of medicines at the clinics, they both either handed out medications to the clients or wrote prescriptions for them to purchase the medicines from pharmacies. Service providers also encouraged STI clients to bring their partners to the clinic for treatment and counseling. Family planning methods were also offered from the clinics as usual. Field workers referred clients with complaints or signs and symptoms of RTIs and STIs to the HFWCs for treatment and counseling. Clients who required advanced medical care for RTIs and STIs were referred to the nearest UHC. To make the referral center more responsive to clients, program managers from the UHC were involved in training the service providers.

NIPORT provided two RTI and STI registers to each HFWC to maintain information about the male and female clients who came to the clinic seeking treatment. Information was recorded about the reasons for the client's visit, what symptoms were presented, what treatment was received, and the details of any referrals that were made. NIPORT and the Population Council staff checked the registers during their regular visits. The data collected from the registers were analyzed and used in the impact evaluation. 


\section{Mobilization of Resources}

During the inventory survey, many needs were identified at HFWC facilities. One major problem was the inadequate supply of medicines, particularly those required for managing RTIs and STIs. To address these issues, meetings of upazila and district level program managers were organized and to the extent possible, these requirements were met from the available public sector resources. The supply of drugs for managing RTIs and STIs, however, remained a problem.

\section{Monthly Field Visits}

Members of the project staff from NIPORT, program managers from each upazila, and the Population Council staff were scheduled to take monthly visits to each experimental HFWC to observe the delivery of RTI and STI services, answer queries from service providers, check information maintained in the RTI and STI client registers, resolve problems, and complete monitoring checklists. However, in reality, these visits did not happen every month. Many monitoring checklists remained incomplete either because scheduled visits were not made or because service providers were not available during the field visit. Only 37 out of 88 monitoring checklists were completed from September 2001 to May 2002. The information collected in the checklists included the total numbers of clients in a given month by age and sex, the number of RTI and STI clients treated by sex, the number of condom acceptors, observations about privacy maintained during consultations, number of partner management sessions, the number of group discussions conducted, and the number of clients referred to upazila and district hospitals. The checklist also included observations on the cleanliness of the center, clinic hours, and the amount of attention given to clients' needs.

\section{LIMITATIONS OF THE STUDY}

Since the study was conducted in a government setting and implemented by NIPORT, a government training and research institution, it was difficult to implement some elements of the evaluation. There was often a lack of coordination between NIPORT and the Directorate of Family Planning. Although both of them are under the same ministry, the administrative structure is different in each institution. For instance, monitoring visits were planned for every month but program managers did not adhere to this schedule. In addition, service statistics such as the number of condom pieces distributed could not be collected. Workers and service providers both distribute condoms in the community, but workers do not submit distribution statistics to the clinics; rather, they report this information directly to the upazila. Under this project, no effort was made to collect this information from the upazila.

Due to resource constraints, some of the planned interventions, such as NSV training for service providers, could not be implemented during the intervention period. Service statistics were not recorded at some clinics for a few months. In two clinics, service providers did not maintain the register properly for three months, as there was no incentive for this work. Clinics needed medicine, the primary form of treatment for RTIs and STIs, to provide ongoing management of these conditions. Program managers had agreed to supply medicines from upazila stores to meet the additional demands incurred during the intervention period. In spite of planning for this 
contingency, clinics frequently ran out of medicine and upazila authorities were unable to replenish stocks.

\section{FINDINGS}

\section{Pre- and Post-Intervention Surveys of Providers}

\section{Background Characteristics of the Service Providers and Field Workers}

A total of 127 service providers (FWV and SACMO) and field workers (FWA, HA, Assistant Health Inspector) were interviewed before the intervention. In the post-intervention phase, 163 providers and workers were interviewed. Table 1 shows the distribution of service providers and workers that were interviewed. An analysis of providers' characteristics revealed no significant differences between the service providers in the experimental and control areas in terms of age and type of training; the only difference observed was in the length of service. The mean age of service providers and field workers in both the experimental and control areas was 39. On average, service providers were posted at the facilities for three years, while field workers worked in the area for more than 12 years.

\begin{tabular}{|c|c|c|c|c|c|c|}
\hline & \multicolumn{3}{|c|}{ Service providers } & \multicolumn{3}{|c|}{ Field workers } \\
\hline & Experimental & Control & All & Experimental & Control & All \\
\hline Pre-test & 19 & 10 & 29 & 75 & 23 & 98 \\
\hline Post-test & 26 & 7 & 33 & 86 & 44 & 130 \\
\hline
\end{tabular}

The number of service providers and field workers interviewed before and after the intervention varied in both the experimental and control areas. This may be due to the transfer of service providers and field workers in the study areas or because they were not available for interviews.

\section{Knowledge about RTIs and STIs}

The majority of the service providers (95\%) and workers (94\%) had received basic training in reproductive health. Interviews with the service providers and field workers showed that 100 percent of the service providers and 91 percent of field workers had heard of RTIs and STIs before the intervention. After the intervention, this awareness increased to 100 percent for the field workers from the experimental area.

Table 2 provides further analysis of the data regarding service providers' knowledge of RTIs and STIs. The data show that before the intervention, the three commonly known STIs-syphilis, gonorrhea, and HIV/AIDS - were known to the service providers working in both experimental and control areas. But very few of them knew about other STIs. In the experimental area, providers' knowledge about other STIs improved significantly after training. Most of them could 
also name chlamydia, trichomoniasis, and genital herpes. No such change was observed in the control area (see Table 2).

Table 2. Distribution of service providers who can name specific STIs

\begin{tabular}{|c|c|c|c|c|c|c|}
\hline \multirow[t]{2}{*}{ Name of STIs } & \multicolumn{3}{|l|}{ Experimental } & \multicolumn{3}{|l|}{ Control } \\
\hline & $\begin{array}{l}\text { Before } \\
\text { Intervention }\end{array}$ & $\begin{array}{l}\text { After } \\
\text { Intervention }\end{array}$ & Z Value & \begin{tabular}{|l|} 
Before \\
Intervention
\end{tabular} & $\begin{array}{l}\text { After } \\
\text { Intervention }\end{array}$ & Z Value \\
\hline Syphilis & 19 & 26 & 0.00 & 10 & 7 & 0.00 \\
\hline Gonorrhea & 18 & 26 & 1.20 & 9 & 7 & 0.10 \\
\hline AIDS & 18 & 21 & 1.36 & 10 & 5 & 1.81 \\
\hline Chlamydia & 0 & 20 & $5.19^{* *}$ & 0 & 0 & 0.00 \\
\hline Genital herpes & 0 & 22 & $5.67^{\star \star}$ & 0 & 0 & 0.00 \\
\hline Chancroid & 2 & 21 & $4.71^{* *}$ & 0 & 3 & $2.28^{*}$ \\
\hline Trichomoniasis & 3 & 22 & $4.65^{\star *}$ & 1 & 0 & 0.41 \\
\hline $\mathbf{N}$ & 19 & 26 & & 10 & 7 & \\
\hline
\end{tabular}

This finding supported the hypothesis that service provider's knowledge can be improved by training. Providers improved their knowledge about most STIs; this result was statistically significant $(\mathrm{p}<.001)$. However, there was some reduction of knowledge about STIs in the control area. This may be due to turnover among service providers in the control area, or to the lack of probing by the researchers.

Although service providers were able to name some of the STIs, they were mostly unaware of the causes of STIs before the intervention. Both service providers and field workers had little knowledge about the origins of STIs and many held misconceptions about the causes. For example, about 12 percent of the field workers believed that RTI and STIs could be transmitted through the use of infected persons' clothing or due to lack of cleanliness. There was no major difference between the providers in the experimental and control areas in terms of understanding of the transmission and prevention of STIs. Moreover, the majority of service providers and field workers confused STIs with HIV/AIDS, particularly in regards to their consequences.

Table 3 presents service providers' and field workers' knowledge of the signs and symptoms of RTIs and STIs. Knowledge among both service providers and field workers significantly increased in the experimental areas following the training; and they retained the knowledge at a reasonable level even nine months after training. As expected, knowledge of the service providers and field workers in the control areas did not change significantly and in a few cases decreased relative to the pre-intervention period. This is mainly because of the small number of providers and the arrival of new providers due to transfers. 
Table 3. Number of service providers and field workers who know the signs and symptoms of male RTIs and STIs, pre- and post-intervention

\begin{tabular}{|c|c|c|c|c|c|c|c|c|c|c|c|c|}
\hline \multirow{3}{*}{$\begin{array}{l}\text { Signs and } \\
\text { Symptoms of } \\
\text { RTIs and STIs }\end{array}$} & \multicolumn{6}{|c|}{ Service Provider } & \multicolumn{6}{|c|}{ Field Worker } \\
\hline & \multicolumn{3}{|c|}{ Experimental } & \multicolumn{3}{|c|}{ Control } & \multicolumn{3}{|c|}{ Experimental } & \multicolumn{3}{|c|}{ Control } \\
\hline & Pre & Post & $\begin{array}{l}\mathrm{Z} \\
\text { Value }\end{array}$ & Pre & Post & $\begin{array}{l}Z \\
\text { Value }\end{array}$ & Pre & Post & $\begin{array}{l}\mathrm{Z} \\
\text { Value }\end{array}$ & Pre & Post & $\begin{array}{l}\text { Z } \\
\text { Value }\end{array}$ \\
\hline $\begin{array}{l}\text { Pus discharge } \\
\text { from urethra }\end{array}$ & 7 & 25 & $4.46^{* *}$ & 4 & 2 & $2.09^{*}$ & 13 & 80 & $9.63^{* *}$ & 1 & 22 & $3.89^{*}$ \\
\hline Ulcer on penis & 2 & 18 & $3.97^{* *}$ & 3 & 0 & $5.00^{* *}$ & 1 & 48 & $7.48^{* *}$ & 1 & 4 & 0.73 \\
\hline $\begin{array}{l}\text { Ulcer on } \\
\text { genital region }\end{array}$ & 6 & 20 & $3.06^{* *}$ & 6 & 2 & 1.28 & 15 & 40 & $3.30^{* *}$ & 2 & 1 & 1.40 \\
\hline $\begin{array}{l}\text { Burning } \\
\text { sensation } \\
\text { during } \\
\text { urination }\end{array}$ & 10 & 21 & $2.03^{*}$ & 7 & 2 & 1.69 & 16 & 78 & $8.76^{* *}$ & 3 & 11 & 1.18 \\
\hline Pain in testis & 7 & 20 & $2.75^{\star}$ & 4 & 0 & $1.96^{*}$ & 10 & 45 & $5.05^{* *}$ & 2 & 3 & 0.29 \\
\hline $\begin{array}{l}\text { Warts on } \\
\text { genital region }\end{array}$ & 4 & 5 & 0.15 & 1 & 1 & 1.75 & 0 & 20 & $4.46^{\star *}$ & 0 & 0 & 0.00 \\
\hline $\begin{array}{l}\text { Semen } \\
\text { discharge from } \\
\text { the penis }\end{array}$ & 10 & 22 & $2.37^{*}$ & 7 & 5 & 0.06 & 27 & 80 & $7.38^{* *}$ & 7 & 31 & $3.42^{*}$ \\
\hline $\begin{array}{l}\text { Itching in } \\
\text { genital region }\end{array}$ & 9 & 22 & $2.78^{*}$ & 5 & 1 & 1.53 & 23 & 64 & $5.26^{* *}$ & 3 & 2 & 1.26 \\
\hline $\mathbf{N}$ & 19 & 26 & & 10 & 7 & & 69 & 86 & & 21 & 40 & \\
\hline
\end{tabular}

${ }^{*}$ Significant at $p<0.001$ percent level, * Significant at $p<0.01$ percent level

The above analysis shows that training increased knowledge of the service providers and field workers about the signs and symptom of RTIs and STIs. As no data were collected on the use of the syndromic approach or knowledge of treatment for different types of STIs, it is difficult to comment on its correct use. However, with all of these limitations, the findings still confirm the hypothesis that training will increase providers' knowledge about RTIs and STIs and their ability to identify the infections based on the symptoms.

Before the intervention, most service providers were either unclear or completely unaware of the health consequences of untreated RTIs and STIs. For example, about 60 percent of the field workers reported death as a consequence of RTIs and STIs. It may be that they confused RTIs with HIV/AIDS. The service providers and field workers were well informed about the transmission and prevention of HIV/AIDS even before the introduction of the intervention. Table 4 shows that the majority of the service providers and field workers were aware of at least three major routes of HIV transmission and how to prevent them. 
Table 4. Percent of service providers who know about transmission and prevention of HIVIAIDS

\begin{tabular}{|c|c|c|c|c|c|c|c|c|}
\hline \multirow{3}{*}{ Route of transmission } & \multicolumn{4}{|c|}{ Experimental } & \multicolumn{4}{|c|}{ Control } \\
\hline & \multicolumn{2}{|c|}{ Transmission } & \multicolumn{2}{|c|}{ Prevention } & \multicolumn{2}{|c|}{ Transmission } & \multicolumn{2}{|c|}{ Prevention } \\
\hline & SP & FW & SP & FW & SP & FW & SP & FW \\
\hline Sex with infected persons & 74 & 53 & 79 & 57 & 80 & 61 & 100 & 83 \\
\hline $\begin{array}{l}\text { Transfusion of infected } \\
\text { blood }\end{array}$ & 74 & 56 & 63 & 37 & 80 & 57 & 70 & 48 \\
\hline $\begin{array}{l}\text { Use of infected syringe and } \\
\text { needle }\end{array}$ & 74 & 71 & 58 & 72 & 90 & 74 & 60 & 52 \\
\hline $\begin{array}{l}\text { Mother to child } \\
\text { transmission }\end{array}$ & 21 & 28 & 0 & 1 & 30 & 9 & 0 & 0 \\
\hline $\begin{array}{l}\text { Intercourse without } \\
\text { condom }\end{array}$ & 11 & 9 & 63 & 71 & 0 & 0 & 30 & 48 \\
\hline Sex with sex workers & 21 & 45 & 0 & 0 & 20 & 70 & 0 & 0 \\
\hline Do not know & 5 & 4 & 5 & 3 & 0 & 4 & 0 & 0 \\
\hline $\mathbf{N}$ & 19 & 75 & 19 & 75 & 10 & 23 & 10 & 23 \\
\hline
\end{tabular}

\section{Providers' Practices}

\section{Use of the Syndromic Approach for Treating RTI and STI Clients}

The syndromic approach (diagnosis and treatment based on client's reported symptoms and signs observed by the provider, but without the use of laboratory testing), which was approved by the World Health Organization (WHO), was used to treat RTI and STI clients in each facility. However, the study did not evaluate the effectiveness and appropriate use of the approach by the service providers. The most common RTI and STI treatment for men was antibiotics, when they were available. Since medicine was often unavailable, clients were often given prescriptions to purchase them from the market. The study did not attempt to measure the proper use of medicine or compliance with the recommended treatment regimen. While the study demonstrates that the HFWC service providers can be trained to use the syndromic approach to manage RTIs and STIs, it is important to evaluate correct and appropriate use of the technique by the service provider. For this, further research is required.

\section{Partner Management}

During interviews, service providers in the experimental areas reported that they advised all clients suffering from STIs to inform their partners about their symptoms and to provide them with appropriate treatment, if necessary. However, partner management was conducted by asking the client to bring the partner to the clinic and by writing a prescription for the partner's treatment. Compliance with the treatment was also not examined in the study.

\section{Counseling About Sexual Health}

Prior to the intervention, several service providers in the experimental and the control areas (11\% and $20 \%$, respectively) were uncomfortable discussing RTIs and STIs and other sensitive sexual health issues with their clients. The number of uncomfortable service providers dropped to zero 
in the experimental clinics and increased to 29 percent in the control area after the intervention. However, this percentage in the control group represents a small absolute number (2).

\section{Service Statistics}

\section{Client Load}

To assess the impact of the intervention on the use of HFWCs, particularly by male clients, service statistics were compiled to calculate the number of clients who received services from the selected HFWCs before and after the intervention period. Service statistics were collected at control and experimental HFCWs for the six months prior to the intervention (January to June 2001) and 12 months afterward (July 2001 to June 2002).

Table 6 provides information regarding the distribution of clients by age and sex. During the sixmonth pre-intervention period, a total of 38,527 clients ( 803 clients per clinic each month) received services from the experimental clinics. The figure increased to 59,943 (1,249 clients per clinic each month) and 68,908 (1,434 clients per clinic each month) in the first six and second six months, respectively, after the intervention. In the control clinics, the corresponding figures were 22,569 clients (940 clients per clinic each month), 20,737 (864 clients per clinic each month) and 30,152 (1,256 clients per clinic each month) respectively. The increased number of clients in the control area over the second six-month period is due mainly to the increased number of clients ages 0 to 14. Table 6 provides a breakdown of these figures by adult male, adult female, total adult clients, and clients ages 0 to 14 .

Table 6. Distribution of all clients including those receiving RTI and STI services, by age and sex (measured in six-month intervals)

\begin{tabular}{|c|c|c|c|c|c|c|}
\hline & \multicolumn{3}{|c|}{ Experimental } & \multicolumn{3}{|c|}{ Control } \\
\hline & $\begin{array}{c}\text { Pre- } \\
\text { interven } \\
\text { tion }\end{array}$ & $\begin{array}{c}1^{\text {st }} \text { six months } \\
\text { post - } \\
\text { intervention }\end{array}$ & $\begin{array}{c}2^{\text {nd }} \text { six } \\
\text { months post- } \\
\text { intervention }\end{array}$ & $\begin{array}{c}\text { Pre- } \\
\text { interven } \\
\text { tion }\end{array}$ & $\begin{array}{c}1^{\text {st }} \text { six months } \\
\text { post- } \\
\text { intervention }\end{array}$ & $\begin{array}{c}2^{\text {nd }} \text { six } \\
\text { months post - } \\
\text { intervention }\end{array}$ \\
\hline \multicolumn{7}{|l|}{ Number of clients served ${ }^{*}$} \\
\hline Adult male $(15$ years +$)$ & 6,262 & 15,861 & 16,578 & 2,524 & 1,673 & 1,786 \\
\hline Adult female $(15$ years +$)$ & 20,415 & 30,136 & 33,249 & 10,143 & 11,082 & 11,831 \\
\hline Total adult $(15$ years + ) & 26,677 & 45,994 & 49,827 & 12,667 & 12,755 & 13,617 \\
\hline Total children aged $(0-14)$ & 11,850 & 13,949 & 19,081 & 9,902 & 7,982 & 16,535 \\
\hline Total clients (all age) & 38,527 & 59,943 & 68,908 & 22,569 & 20,737 & 30,152 \\
\hline \multicolumn{7}{|c|}{ Monthly average clients per clinic ${ }^{*}$} \\
\hline Adult male (15 years + ) & 131 & $330^{* *}$ & $345^{\star *}$ & 105 & 70 & 74 \\
\hline Adult female $(15$ years +$)$ & 425 & $628^{* *}$ & $693^{* *}$ & 423 & 462 & 493 \\
\hline Total adult ( 15 years + ) & 556 & 958 & 1,038 & 528 & 531 & 567 \\
\hline Total children aged $(0-14)$ & 247 & 291 & 398 & 413 & 333 & $689^{* *}$ \\
\hline Total clients (all age) & 803 & 1,249 & 1,436 & 941 & 864 & 1,256 \\
\hline
\end{tabular}

${ }^{*}$ Number of clients and average are based on 8 clinics in experimental area and 4 clinics in control area.

${ }^{* *} t$ test was significant at $p<0.001$ percent level 
The analysis shows that the total number of male clients (ages 15 and above) who attended the experimental HFWCs increased substantially after the intervention. For instance, the average number of male clients per clinic each month increased threefold, from 131 to 330 in the first six months of the intervention and remained at 345 per clinic each month during the second six months of the intervention. The change in the average number of male clients who attended the clinic each month is statistically significant $(\mathrm{t}=7.51, \mathrm{p}<.001)$.

In contrast, in the control areas, the corresponding figure during the pre-intervention period was 105. This declined to 70 during the first six months and remained almost at the same level (74) over the second six months of the intervention period. These results confirm the hypothesis that the number of male clients will increase significantly when RTI and STI services are added in HFWCs and men are encouraged to use them.

It is encouraging to note that during the same period, the number of adult female clients and children (ages 0 to 14) also increased substantially. The findings presented in Table 6 show that the average adult female patient load increased from 425 to 628 and 693 per month during the first and second six-month periods of the intervention. The difference in the average of pre- and post-intervention female clients in the experimental clinics is statistically significant $(t=4.652$, $\mathrm{p}<.001)$. No such significant increase was observed in the control areas. This finding confirms the hypothesis that encouraging male clients to attend clinics and providing services for them will not adversely affect services for female clients (see Figures 1 and 2).

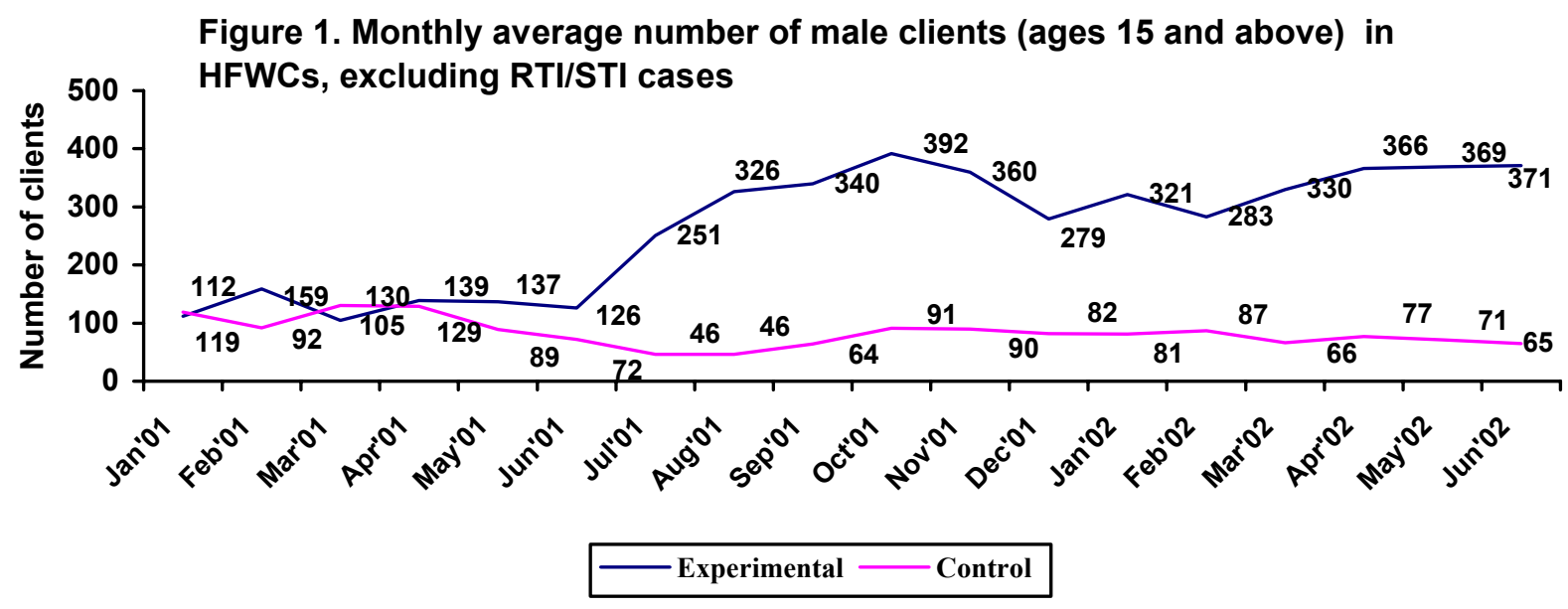




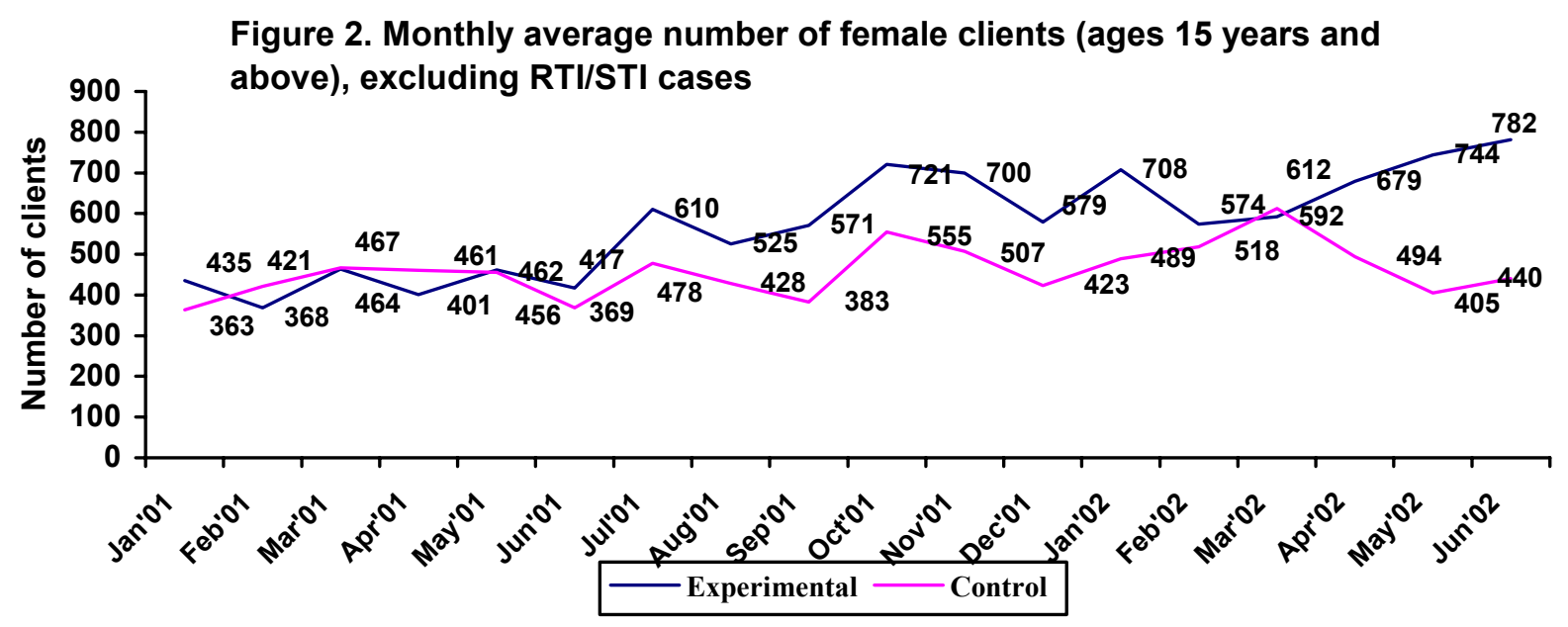

The study shows that, in general, the interventions helped to increase use of the clinics and increased the monthly average number of clients from 803 clients per clinic each month to 1436 clients in the intervention clinics. Thus, one year after the intervention, overall use of the clinics increased by 79 percent. The corresponding increase for the adult population (ages 15 and above) was still high (87\%). The control clinic also registered an increase in the number of clients who received services during the second six months of the intervention period from 941 to 1256 . This increase was due largely to a steep rise in the number of clients ages 0 to 14 . The reason for this large increase in the number of child clients is not clear, but it was observed in both the experimental and the control clinics. On the other hand, the increase in the number of adult clients was very modest $(7 \%)$.

\section{Number of RTI and STI Cases}

Most (98\%) of the adult male and adult female clients came to the HFWCs for treatment of general health problems. Only about 2 percent of the clients sought treatment specifically for problems related to RTIs and STIs. However, the data presented in Table 7 and Figure 3

demonstrate that in the experimental clinics, the number of male clients treated for symptoms of RTIs and STIs increased from 44 to 263 in the first six months of the intervention. In the intervention's second six months, the number of clients remained stable around 255 . Interestingly, the corresponding increase in female clients was still higher - from 37 in the six-month pre-intervention period to 469 , and then to 624 during
Table 7. Distribution of STI/RTI clients treated before and after the intervention

\begin{tabular}{|c|c|c|c|}
\hline & \multicolumn{3}{|c|}{ Experimental } \\
\hline & $\begin{array}{c}\text { Pre- } \\
\text { interven } \\
\text { tion }\end{array}$ & $\begin{array}{l}1^{\text {st }} \text { six months } \\
\text { post- } \\
\text { intervention }\end{array}$ & $\begin{array}{c}2^{\text {nd }} \text { six } \\
\text { months post- } \\
\text { intervention }\end{array}$ \\
\hline \multicolumn{4}{|c|}{ Total number of RTI/STI clients treated (15 years +$)^{*}$} \\
\hline Adult male & 44 & 263 & 255 \\
\hline Adult female & 37 & 469 & 623 \\
\hline Total clients & 81 & 732 & 878 \\
\hline \multicolumn{4}{|c|}{ Monthly average clients clinic (15 years +$)^{*}$} \\
\hline Adult male & 0.9 & $5.5^{* *}$ & $5.3^{* *}$ \\
\hline Adult female & 0.8 & $9.8^{\star \star}$ & $13.0^{* *}$ \\
\hline Total clients & 1.7 & $15.3^{* *}$ & $18.3^{* *}$ \\
\hline \multicolumn{4}{|c|}{$\begin{array}{l}\text { *Number and average based on } 8 \text { experimental and } \\
4 \text { control clinics } \\
{ }^{* *} p<.001\end{array}$} \\
\hline
\end{tabular}


the first and second six-month post-intervention period.

Further analysis indicates that prior to the intervention, the clinics were treating on average one male and one female RTI and STI client every month. After the intervention, this monthly average increased to more than five males and 13 female clients. No such change was observed in the control clinics. During the study period, none of the control clinics received any RTI and STI clients. The study thus confirmed the hypothesis that, if RTI and STI services are introduced in the HFWC and men are informed about them, they will use the services. The findings further indicate that women will also benefit from these interventions and seek treatment for RTIs and STIs.

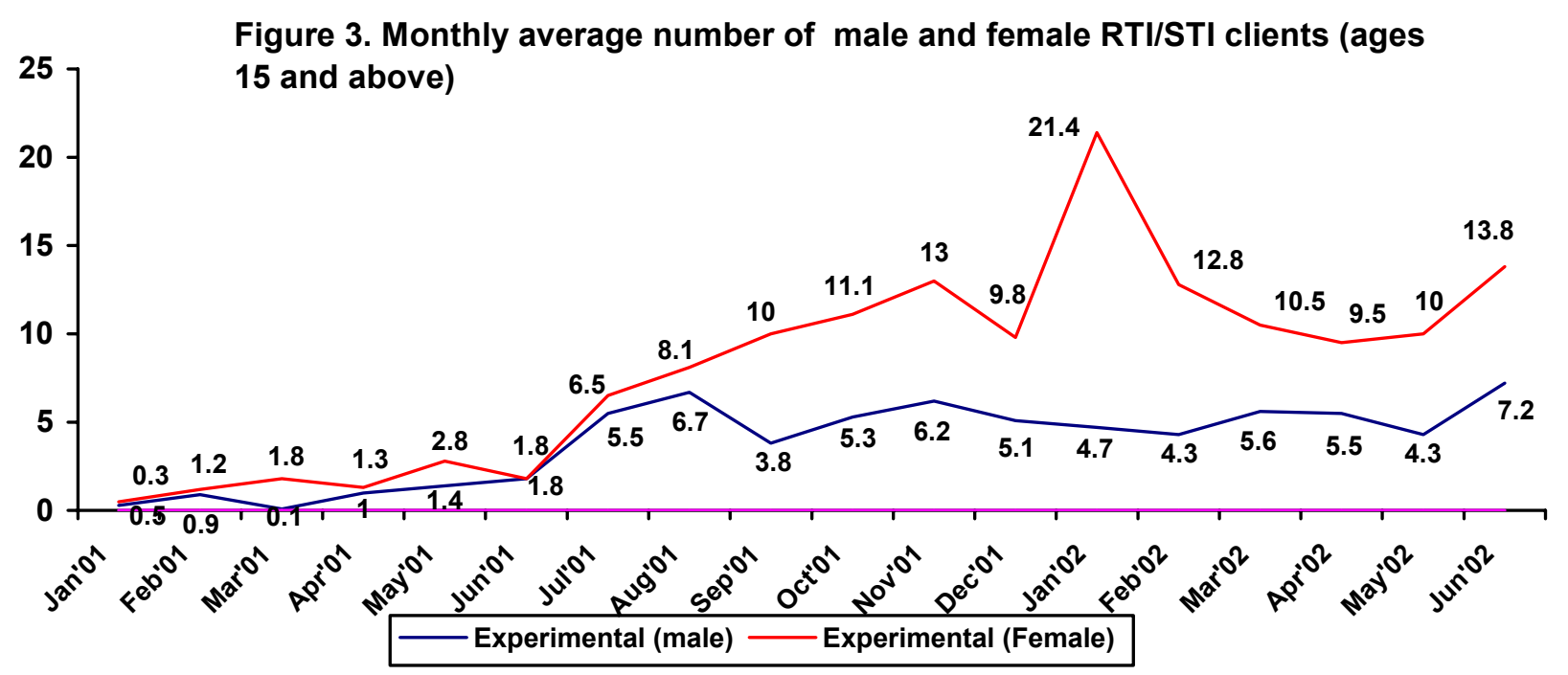

\section{Symptoms Reported by Male RTI and STI Clients}

It was very difficult to get a complete picture of individual clients' complaints from the service register as service providers often combine complaints. Moreover, sometimes providers only write a general diagnosis, such as "STI." However, analysis of the service register for the 518 male clients showed that urethral discharge (82\%), penile ulcerative problems $(11 \%)$, and other problems such as burning sensation and painful urination $(22 \%)$ were the most frequently treated RTI and STI symptoms.

\section{Condom Use}

Service statistics maintained at the HFWCs could not provide information about condom distribution. Service providers are reluctant to take condoms from UHC, as they have to purchase them with their own funds and subsequently recover the amount by selling them to their clients. Providers feel uncomfortable committing their funds by buying condoms in advance. They do keep a few condoms in stock, but only for display purposes. Furthermore, field workers report to the FPI and UHC and not to the HFWC about the distribution of condoms. Therefore, it was difficult to determine the exact number of condoms that were distributed in the project areas. No effort or arrangement was made to collect this information under the present project. However, analysis of exit client data showed that about 5 percent of the male clients came to the HFWC for 
family planning methods. This is an interesting observation as men rarely go to the HFWC to pick up condoms. In the control clinics, only 1 percent of exiting clients had come to get condoms. Considering the small number of cases both in the experimental and control groups, it is difficult to conclude that the difference between the groups was statistically significant.

Focus group discussions revealed the widespread prevalence of misconceptions about male contraceptive methods. The majority of the informants in the discussions believed that family planning is a woman's issue. Some even considered it a sin to use condoms. One informant said:

Let me tell you about my experience. I have been married for 10 years. I have five children and may Allah keep all of them in good health! I have never used any natural or artificial contraceptive method. Using condoms will keep the wife dissatisfied and unhappy. Moreover, discharging semen somewhere else (outside the woman's body) is a Gunnah (sin). You know, [receiving semen is] actually wife's Haaqk (right). I cannot adopt any family planning method. [My wife] may use some methods but I will not. If she uses some method, it is her sin, not mine.

\section{Observations from Client Exit Interviews}

\section{Background Characteristics of the Exit Clients}

A total of 286 male (220 experimental, 66 control) and 300 female (175 experimental and 125 control) clients were interviewed at the clinics after they had received the services. All of these interviews were conducted after implementing the interventions and were held over several months. Table 8 shows that there is no significant difference in the age, marital status, educational status, and occupation of the clients in the experimental and control areas. The mean age of the male clients was 35 years in the experimental areas and 33 years in the control areas. The mean duration of schooling was six and five years in the experimental control areas, respectively. In terms of occupations, men were most commonly farmers, businessmen, or students, in that order. Approximately two-third of the male clients were married.

\section{Table 8: Background characteristics of male $(M)$ and female $(F)$ clients (percentage)}

\begin{tabular}{|c|c|c|c|c|}
\hline \multirow[t]{2}{*}{ Characteristics } & \multicolumn{2}{|c|}{ Experimental } & \multicolumn{2}{|c|}{ Control } \\
\hline & $\begin{array}{l}\mathrm{M} \\
\%\end{array}$ & $\begin{array}{l}F \\
\%\end{array}$ & $\begin{array}{l}\mathbf{M} \\
\%\end{array}$ & $\begin{array}{l}\mathbf{F} \\
\%\end{array}$ \\
\hline \multicolumn{5}{|l|}{ Age } \\
\hline Less than 20 & 13 & 10 & 17 & 8 \\
\hline $20-29$ & 28 & 47 & 26 & 50 \\
\hline $30-39$ & 21 & 32 & 27 & 30 \\
\hline $40-49$ & 22 & 11 & 21 & 12 \\
\hline 50 and above & 16 & - & 9 & - \\
\hline Mean & 35 & 28 & 33 & 28 \\
\hline $\mathrm{SD}^{*}$ & 14 & 7 & 12 & 7 \\
\hline \multicolumn{5}{|l|}{ Education } \\
\hline None & 25 & 49 & 29 & 54 \\
\hline $1-5$ & 21 & 31 & 26 & 30 \\
\hline $6-10$ & 41 & 18 & 36 & 13 \\
\hline $11-12$ & 9 & 2 & 3 & 3 \\
\hline More than 12 & 4 & - & 6 & - \\
\hline Mean & 6 & 3 & 5 & 3 \\
\hline $\mathrm{SD}^{*}$ & 5 & 4 & 5 & 3 \\
\hline \multicolumn{5}{|l|}{ Occupation } \\
\hline Service & 11 & 2 & 12 & 2 \\
\hline Business & 20 & 1 & 20 & 2 \\
\hline Farmer & 33 & - & 35 & - \\
\hline Day labor & 14 & 3 & 12 & 2 \\
\hline Student & 16 & 1 & 14 & 1 \\
\hline Unemployed & 6 & - & 9 & - \\
\hline Housewife & - & 86 & - & 91 \\
\hline Maid servants & & 7 & - & 2 \\
\hline \multicolumn{5}{|l|}{ Marital Status } \\
\hline Married & 70 & 89 & 65 & 92 \\
\hline Unmarried & 29 & 2 & 33 & 2 \\
\hline Widow & 1 & 5 & 2 & 2 \\
\hline Divorced & - & 2 & - & 2 \\
\hline Separated & 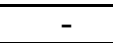 & 2 & - & 2 \\
\hline $\mathbf{N}$ & 220 & 175 & 66 & 125 \\
\hline
\end{tabular}




\section{Purpose of Current HFWC Visit}

Analysis of the data from exit interviews showed that more than 90 percent of male clients visit HFWCs for general health care (see Table 9). While none of the male clients in the control areas came for treatment of RTIs and STIs, 20 male clients (about 9 percent, $\mathrm{N}=220$ ) in the experimental areas came with RTI- or STI-related problems such as urethral discharge (2.7\%), frequent urination $(3.2 \%)$, and soreness of the penis $(2.3 \%)$. About 5 percent of the male clients in the experimental area, as compared to 1 percent in the control area, mentioned family planning as the reason for visiting HFWCs. The remaining male clients (86\%) had come to the clinics for general health problems. Among the female clients, about 45 percent had come for treatment of general health problems, about 22 percent for contraceptives, while the remaining 33 percent had come for treatment of RTI and STI-related symptoms. In contrast, in the control area about 64 percent of the female clients had come for general health problems and 18 percent each to receive treatment for RTIs and STIs and to obtain family planning (see Table 9).

\section{Sources of Information about RTI and STI Services}

Table 9. Percent distribution of clients by reasons for current visit to HFWC

\begin{tabular}{|l|c|c|c|c|}
\hline \multirow{2}{*}{} & \multicolumn{2}{|c|}{ Experimental } & \multicolumn{2}{c|}{ Control } \\
\cline { 2 - 5 } & Male & Female & Male & Female \\
\hline $\begin{array}{l}\text { Symptoms consistent } \\
\text { with RTI and STI }\end{array}$ & 9 & 33 & - & 18 \\
\hline Collection of FP method & 5 & 22 & 1 & 18 \\
\hline $\begin{array}{l}\text { Problems with general } \\
\text { health }\end{array}$ & 86 & 45 & 99 & 64 \\
\hline $\mathbf{N}$ & $\mathbf{2 2 0}$ & $\mathbf{1 7 5}$ & $\mathbf{6 6}$ & $\mathbf{1 2 5}$ \\
\hline
\end{tabular}

Male and female clients learned about the availability of RTI and STI services at the HFWC from different sources. Among the 220 male clients that were interviewed in the experimental areas, $191(87 \%)$ had heard about the availability of treatment for RTIs and STIs at the HFWCs. Findings presented in Figure 4 show that the common sources of information for men were group discussions ( $72 \%$ ), field workers (57\%), service providers (55\%), and BCC materials such as posters, leaflets, and signboards (21\%). On the other hand, among the 201 female exit clients who had heard of RTI and STI services, more than 90 percent had heard about them from service providers $(95 \%)$ and field workers $(91 \%)$.

About 87 percent of the male and 58 percent of the female clients mentioned that they had seen the poster or signboard about clinical services. In male focus group discussions, several informants suggested that the use of poster and billboards in public places, community meetings, motivation by male workers and distribution of leaflets with important messages would enhance the use of HWFC services by men. They thought that announcements made over loudspeakers and posters would be an

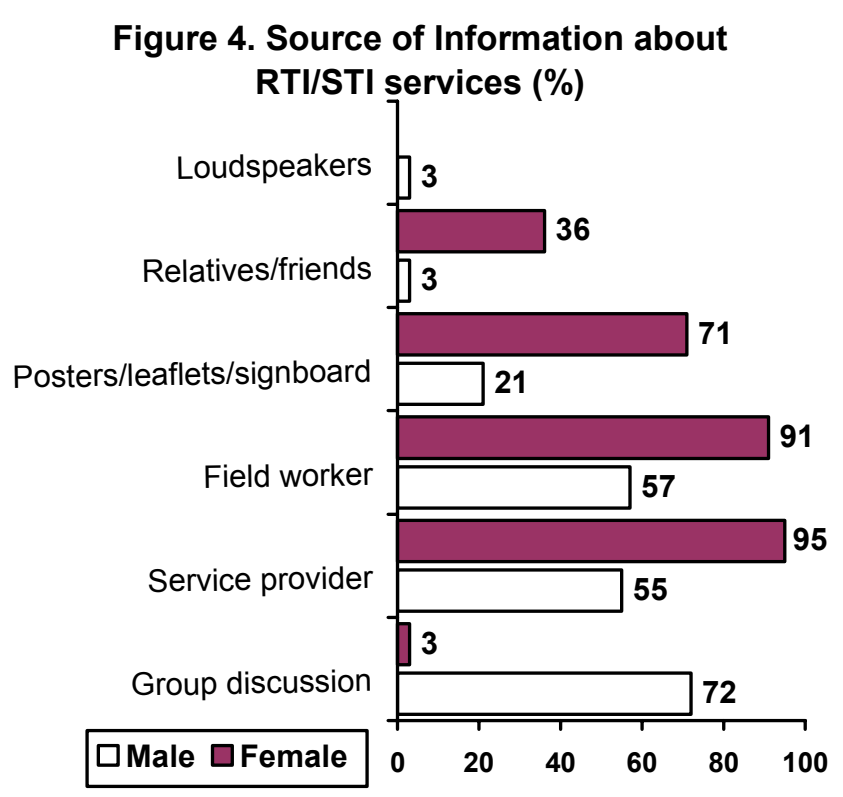


effective means of raising awareness. One of the informants said:

Encouraging people to use HFWC is not difficult. Make services available and then inform the community people. If needed do loudspeaker announcements or hang posters. You will see, you will get so many clients that providing services will be difficult.

\section{Treatment-Seeking Behavior of Male Clients}

In the exit interview, all male clients were asked whether they or their wives had experienced any symptoms of RTIs and STIs in the past three months and if so, how they managed them. Table 10, which presents the health-seeking behaviors of the men, shows that men in both the experimental and control areas suffered from RTIs and STIs. Out of the total 219 men interviewed in the experimental area, $119(54 \%)$ mentioned one or more symptoms of RTIs and STIs. The corresponding percentage in the control area was 86 percent. However, approximately

Table 10. Percent distribution of male clients who experienced symptoms of RTIs and STIs in the previous three months and their treatment-seeking behavior

\begin{tabular}{|l|c|c|c|c|c|c|}
\hline \multirow{2}{*}{ Signs and symptoms } & \multicolumn{5}{|c|}{ Experimental } & \multicolumn{3}{c|}{ Control } \\
\cline { 2 - 7 } & $\begin{array}{c}\text { Percent } \\
\text { with } \\
\text { symptoms }\end{array}$ & $\begin{array}{c}\text { Percent } \\
\text { received } \\
\text { treatment* }\end{array}$ & $\begin{array}{c}\text { Percent } \\
\text { consulted } \\
\text { qualified } \\
\text { providers * }\end{array}$ & $\begin{array}{c}\text { Percent } \\
\text { with } \\
\text { symptoms }\end{array}$ & $\begin{array}{c}\text { Percent } \\
\text { received } \\
\text { treatment* }\end{array}$ & $\begin{array}{c}\text { Percent } \\
\text { consulted } \\
\text { qualified } \\
\text { providers * }\end{array}$ \\
\hline $\begin{array}{l}\text { Semen discharge from } \\
\text { the penis }\end{array}$ & $16(219)$ & $47(35)$ & $26(16)$ & $17(66)$ & $45(11)$ & $27(5)$ \\
\hline $\begin{array}{l}\text { Pus discharge through } \\
\text { urethra }\end{array}$ & $5(219)$ & $58(11)$ & $36(6)$ & $6(66)$ & $75(4)$ & $25(3)$ \\
\hline $\begin{array}{l}\text { Burning sensation } \\
\text { during urination }\end{array}$ & $15(219)$ & $55(33)$ & $21(18)$ & $19(66)$ & $31(13)$ & $23(4)$ \\
\hline $\begin{array}{l}\text { Pain during } \\
\text { intercourse }\end{array}$ & $6(219)$ & $38(13)$ & $15(5)$ & $8(66)$ & $40(5)$ & $20(2)$ \\
\hline Ulcer on the penis & $4(219)$ & $75(9)$ & $44(7)$ & $15(66)$ & $60(10)$ & - \\
\hline Pain in the testis & $8(219)$ & $33(18)$ & $22(6)$ & $21(66)$ & $43(14)$ & $36(6)$ \\
\hline $\mathbf{N}$ & $\mathbf{2 1 9}$ & & & 66 & & \\
\hline
\end{tabular}

Figures in parenthesis show the number of base cases

* Percentage is based on the number who experienced symptoms

half of the men did not use any clinical services for treatment. About 50 percent of men who sought services went to qualified providers including a doctor, SACMO, and FWV. The analysis indicates that symptoms like pus discharge from the urethra and ulcer on the penis are taken more seriously, with more than 60 percent of men seeking treatment. Less than half sought medical treatment for other symptoms, and only between 20 to 30 percent sought treatment from a qualified person for these symptoms. The stigma associated with STIs often discourages people from seeking medical treatment from government clinics where they know many of the providers. As a result, men use private sources for treatment, often untrained traditional health providers. Similar kinds of treatment-seeking behavior were observed in the control area. Informants in focus group discussions also substantiate these findings. As one of the male informants during a pre-intervention said: 
Most victims tried to hide the "secret disease" and sought treatment secretly from a village doctor, a kabiraj, or purchased medicines from the pharmacy without any prescriptions. If they are not cured, then they go to a qualified doctor or to a hospital. By that time it became worse.

No significant difference was observed between clients of experimental and control clinics in their health-seeking behavior after the intervention.

\section{Quality of Services}

The quality of care provided by HFWCs was assessed through regular monitoring visits, the inventory survey, and feedback from exit interviews. The perception of community members about health services was also assessed. Inventory surveys revealed that both experimental and the control clinics had adequate quantities of most medical instruments and supplies required to examine clients with RTIs and STIs. This included items like Sims speculum, holding forceps, Galli pot, instrument tray, gloves, torch light, cotton, lifter, autoclave, boiling pot, stove, bleaching powder, dettol/savlon, and kerosene oil. Some of the service providers reported that items that were needed regularly such as savlon, cotton, and kerosene were frequently out of stock. However, the providers rarely needed these items to diagnose cases of RTIs and STIs among male clients.

Those who participated in the focus group discussions before the intervention, in both the experimental and the control areas, reported that the services offered at HFWCs were mostly unsatisfactory, except for family planning services. According to the discussants, men do not go to HFWCs for treatment because of shortages of medicine, absence of qualified doctors, rudeness of service providers, irregular clinic hours, unhygienic conditions, and the lack of treatment facilities for men. After the intervention, however, informants in the experimental area pointed out that the quality of services was generally good but the main drawback was still the lack of qualified doctors. One informant said:

If a good doctor is present at HFWCs, then the situation will improve regardless of the availability of medicine. At least they will get examination and free prescription from a qualified doctor. They can always buy the medicine from the market.

At the monthly visits, it was observed that the service providers maintained privacy and confidentiality during consultations in the experimental areas. Examination rooms in the experimental HFWCs were also found to be clean. In contrast, the situation in the control area, as reported by a community leader, was not satisfactory.

This HFWC is in a terrible condition, doctors have awful manners (or lack communication skills), people can not get any medicine, and the centers never open on time or remain open on schedule.

These isolated comments from focus group discussions, however, should be considered with caution. Most of the responses from the exit interviews in both areas were positive regarding the 
quality of care. The majority of the male and female exit clients from both the experimental and control areas acknowledged that the services that they received were good. Interviewers asked clients a series of questions about the quality of services they received from the HFWC. As Table 11 reveals, clients expressed satisfaction with the amount of attention they received from the providers, providers' manners, maintenance of privacy, and overall management of the clinic. However, water supply and the cleanliness of the toilet remained a major problem for all of the clinics in both experimental and control areas. On all of these parameters, the responses of the clients from the experimental and control groups did not differ significantly. Thus, the findings remain inconclusive about the impact of the intervention on the quality of services. This is not surprising because the study did not focus on the broader aspects of quality of care.

\section{Service Hours}

About 97 percent of the male clients in the experimental and control areas reported that the clinic's present hours were convenient for them and that there was no need to change them (see Table 11). After implementation of the interventions, informants in the focus group discussions gave similar feedback. Moreover, they emphasized that the quality of services and the credibility of the provider were the central issues rather for them than the 'timing'. One informant commented:

Table 11. Percent distribution of opinions of male and
female exit clients about the service delivery
\begin{tabular}{|l|c|c|c|c|}
\hline \multirow{2}{*}{ Issues of concern } & \multicolumn{2}{|c|}{ Experimental } & \multicolumn{2}{c|}{ Control } \\
\cline { 2 - 5 } & Male & Female & Male & Female \\
\cline { 2 - 5 } & Yes & Yes & Yes & Yes \\
\hline $\begin{array}{l}\text { Service provider listen to } \\
\text { client's problems with attention }\end{array}$ & 99 & 98 & 97 & 90 \\
\hline $\begin{array}{l}\text { Maintained privacy during } \\
\text { consultation }\end{array}$ & 84 & 86 & 94 & 86 \\
\hline $\begin{array}{l}\text { Service provider behavior was } \\
\text { good }\end{array}$ & 99 & 99 & 98 & 86 \\
\hline Clinic was clean & 98 & 99 & 85 & 98 \\
\hline Water supply was good & 96 & 46 & 89 & 26 \\
\hline Toilet was clean & 29 & - & 35 & - \\
\hline $\begin{array}{l}\text { Existing time was suitable for } \\
\text { male client }\end{array}$ & 97 & - & 97 & - \\
\hline $\begin{array}{l}\text { Service can be given to both } \\
\text { male and female clients } \\
\text { together from the same clinic }\end{array}$ & 99 & 91 & 74 & 22 \\
\hline $\begin{array}{l}\text { Client was satisfied with the } \\
\text { services }\end{array}$ & 97 & 97 & 97 & 86 \\
\hline $\mathbf{N}$ & $\mathbf{2 2 0}$ & $\mathbf{1 7 5}$ & $\mathbf{6 6}$ & $\mathbf{1 2 5}$ \\
\hline
\end{tabular}

What's the use of having a timetable? If we don't get proper treatment and medicine, what's the use if the providers' attend [the] clinic_[on a] timely [basis]? If service is good, and provided by [a] qualified doctor anytime men can go for the services

However, a few informants in both the experimental and control areas felt that the hours could be extended from 2:30 pm to 5:00 pm. A few adolescent informants also suggested keeping the HFWC open until 5:00 pm. The findings indicate that including male reproductive health services at HFWC enhances use of the services; adjustment or change in clinic timing is not required. 


\section{Acceptability of Male Clients at HFWCs}

All men (100\%) and most women (91\%) in the experimental areas reported that the presence of clients of the opposite sex did not make them uncomfortable. Similarly, about 74 percent of the male and 22 percent of the female clients in the control areas approved of including services for male clients (see Table 11). This positive reaction, particularly in the experimental area, is a sign of the community's endorsement of integrating services for men within a female-focused service delivery system. This was also supported by findings from the focus groups. One male informant said:

What is the problem? If male-female can take service together from big hospital, why they will not be able to do the same from HFWC? I didn't see any problem. I send my wife and relatives to take services from the same clinic.

One female client expressed similar feelings and said:

This center is not only for us [women]. If males come, what is our problem? They will take their service; we will take ours. I also bring my husband here. I don't bother who said what.

A relatively much larger proportion of women (91\%) in the experimental area approved of including services for male clients than in the control area $(22 \%)$. This suggests that as long as services for men and women are not integrated that women might have some hesitation about attending the clinic but once they experience it (as in the experimental area), most of their hesitation disappears. These findings support the hypothesis that services for men and women could be provided at the same clinic, and that it will not adversely affect the number of female clients that seek services from HFWCs. Rather, providing services for both men and women will make HFWC services more efficient.

\section{Findings from the Review Workshops}

Two review workshops, one each in the first and last quarter of the intervention period, were held with program managers and service providers to assess their reaction to providing male reproductive health services. Participants discussed their experiences with the project management. The review meetings were conducted using a participatory approach. In the first review meeting after three months of interventions, all efforts were made to examine the scope and feasibility of making improvements in implementing the interventions. During this meeting, many important decisions were taken to improve the delivery of male reproductive health services (see Box 1). One of the crucial decisions was to give providers practical skills at the teaching hospital. Providers felt strongly

\section{Box 1. Decisions taken in the first review} workshop

- The experimental HFWCs need to introduce service registers.

- The upazila teams should develop the BCC materials.

- $\quad$ Service providers need more training on the diagnosis and treatment of RTI and STIs at a teaching hospital.

- At least 50 group discussions should be organized in each experimental union.

- The monitoring checklist needs to be finalized. 
that because of the low turnover of STI clients, that their practical training at upazila was not sufficient to provide STI services to clients. Furthermore, to strengthen the educational effort, during the first review meeting, the upazila managers took responsibility for developing the BCC materials.

The second review workshop was held in July 2002 at the NIPORT headquarters in Dhaka. Approximately 50 participants HFWCs' providers, program managers from the Directorate of Family Planning, senior government officials from the Ministry, and the project teams from NIPORT and the Population Council attended the workshop. The objectives of the workshop were to share experiences and lessons learned thus far and to review what further action should be taken to improve the performance. This meeting was held in the third quarter of the intervention period when the activities were coming to an end. The participants made several recommendations:

- Make adequate medicine supplies available at each clinic.

- Provide clinical training about RTIs and STIs and integrate it with the theoretical training and build a refresher course into the program.

- Use group discussions to raise awareness about RTI and STI issues.

- Keep clinic hours the same, as there is no need to modify the schedule to provide reproductive health services for men (see Box 2).

\section{RESULTS OF HYPOTHESES TESTED}

Table 12 presents the results of the hypotheses that were tested in the study. Findings presented in this report suggest that service providers' knowledge can be improved through training. Moreover, if services for men are included at HFWCs and publicized, men will use these services. The study also established that including male RTI and STI services into the HFWCs, which are primarily female-focused service delivery centers, would not have a negative effect on women's attendance at the centers or on the services they receive there. Instead, as the study shows, it leads to an increase in the use of the HFWCs by female clients and an overall increase in the efficiency and use of HFWCs. Further, clinic do not need to change their hours as they are convenient for most men. The presence of clients of the opposite sex did not make either men or women uncomfortable. 
Table 12. Summary of the results of hypotheses tested

\begin{tabular}{|c|c|}
\hline Hypotheses & Status \\
\hline $\begin{array}{l}\text { The intervention will augment service providers' technical } \\
\text { knowledge about male reproductive problems and } \\
\text { syndromic management of RTIs and STIs. }\end{array}$ & Confirmed \\
\hline $\begin{array}{l}\text { - If male reproductive health services are included within the } \\
\text { female focused HFWCs and men are made aware of them, } \\
\text { they will use the services. }\end{array}$ & Confirmed \\
\hline $\begin{array}{l}\text { Inclusion of male reproductive health services at HFWCs } \\
\text { will not have any adverse effect upon the number or } \\
\text { services of female clients seeking treatment from the same } \\
\text { clinics. }\end{array}$ & Confirmed \\
\hline $\begin{array}{l}\text { - Interventions will lead to an increase in the number of male } \\
\text { clients with RTls and STls at experimental clinics. }\end{array}$ & Confirmed \\
\hline $\begin{array}{l}\text { - There is no need to alter the working hours of HFWCs to } \\
\text { accommodate male clients, particularly those with RTIs and } \\
\text { STIs. }\end{array}$ & Confirmed \\
\hline $\begin{array}{l}\text { - Interventions will help increase condom use and } \\
\text { acceptance of NSV. }\end{array}$ & $\begin{array}{l}\text { No training in NSV was } \\
\text { given. Condom use could } \\
\text { not be ascertained }\end{array}$ \\
\hline
\end{tabular}

\section{UTILIZATION OF THE STUDY FINDINGS}

Dissemination seminars were held in October 2002 and June 2003 to share the project findings. Senior officials of the Ministry of Health and Family Welfare, reproductive health experts, development partners, representatives from NGOs, and community members were present at these seminars. The Minister and the Secretary of the Ministry of Health and Family Welfare were also present at one of the seminars.

The results of the study confirmed the feasibility of integrating male services, particularly for treatment of RTIs and STIs, in the existing female-focused service delivery system. The research demonstrated that men would use the services provided in the HFWC if they were aware of them. It also indicated that paramedics can be trained to provide preliminary RTI and STI services using a syndromic approach with men. In response to the encouraging study findings, the Secretary of the Ministry of Health and Family Welfare has asked NIPORT to expand the provision of RTI and STI services for men to $100-150$ HFWCs. At the same time, the Population Council has been asked to provide technical assistance in scaling up the program (see letter in the Appendix).

Several meetings have since been held with the relevant departments about expanding male reproductive health services. The Directorate of Family Planning has agreed to bear some of the costs of the services such as the information, education, and communication (IEC) program and the cost of medicine. However, some of the interventions, including training service providers, will require allocate additional resources. The Directorate is trying to generate further funds by negotiating with international bilateral agencies and hopes to initiate the activity soon. The government's decision to accept financial responsibility represents progress towards sustainability of the services. The Ministry of Health and Family Welfare intends to include male health services in all HFWCs if the initial 100 to 150 HFWCs show significant improvements in service delivery and clinic utilization. 


\section{CONCLUSIONS AND RECOMMENDATIONS}

The findings of this OR project provide valuable insights into the feasibility of meeting the reproductive health needs of men and enhancing the use of HFWCs by both women and men. Pre-intervention data from both experimental and control areas showed that although a few men were using the HFWCs, their visits were limited to seeking services only for general health problems. The number of male clients was also quite small as the HFWC is primarily known as a women's health facility. The study revealed that men's use of these centers could be increased substantially if services for the treatment of RTIs and STIs are made available and if IEC activities encourage men's use of these services. Apart from an increase in the number of male clients, the unexpected rise in the number of female clients indicates that both male and female clients can be served from the same facility. This type of programmatic change in the delivery of services would not have an adverse effect on women's accessibility and use of health services. In fact, an increase in the number of female clients at HFWCs suggests more effective use of health facilities and a corresponding decrease in the cost of treatment per client. Thus, the findings indicate that enhanced use of HFWCs by men and the introduction of services for RTIs and STIs at the clinics can be achieved without imposing a heavy burden on government resources. For instance, most of the medical tools (except medicine and lab tests) that are required for diagnosis and treatment are available in the centers. Financial assistance is mainly required for training staff; this can easily be carried out at government facilities under the management of existing staff. Some additional resources are also required to ensure that there is sufficient medicine available at the clinics to manage cases of RTIs and STIs. Further, findings indicate that including male clients will require very little modification in the delivery system as neither different hours nor separate facilities are needed at HFWCs. This demonstrates a win-win situation for all of the concerned parties - women, men, and program managers.

However, some notes of caution are also essential before scaling up this program. The study demonstrated that service providers could be trained in how to manage RTIs and STIs. However, theoretical training alone is insufficient for the effective delivery of RTI and STI services. Good clinical training and demonstration are essential for case management of RTIs and STIs in clients using the syndromic approach. The practical training should be conducted at a place where providers would have enough RTI and STI cases to observe and practice the syndromic approach for managing both male and female clients. Another note of caution is that this study did not have adequate information to judge how long the providers continued using the syndromic approach systematically once the training ended, or the degree to which they followed the prescribed algorithms.

The study revealed that before the training, service providers' knowledge of STIs was limited to syphilis, gonorrhea, and HIV/AIDS. Because of the publicity given to HIV/AIDS as an STI, many service providers presumed that the transmission, prevention, and consequences of all STIs are similar to those of HIV/AIDS. For example, many service providers thought that all RTIs and STIs could lead to death. This underscores the need for provider training to clearly distinguish between HIV/AIDS and other RTIs and STIs. It was also observed that a considerable number of service providers were reluctant to address sexual issues during client counseling. These finding suggest that service providers require training in communication skills to make them more effective counselors and more able to discuss sex and sexuality. Providers will need several short 
refresher courses and supportive supervision, rather than one short training course that covers several topics, to carry out effective communication and counseling sessions.

Since HFWCs continue to focus mainly on mothers and children, the inclusion of male clients in these centers requires targeted BCC materials. Likewise, the availability of the new services has to be publicized in the community. The materials can provide information about the services and raise awareness about the signs and symptoms of RTIs and STIs among men, their consequences, and necessary interventions. The study confirmed that focused awareness-raising activities were successful in increasing the number of male clients who went to HFWCs seeking treatment for both general health and problems related to RTIs and STIs. An increased client load for RTI and STI treatment also created the demand for additional medicines. However, as the required medicines for treating RTIs and STIs often remained in short supply, the clients were prescribed medicines that they could purchase from the market. In the present study, it was not possible to assess clients' compliance either in using the medicine or managing their partner's symptoms. It is recommended that these issues be carefully evaluated during any scale-up of the interventions.

Both because of resource constraints and procedural problems, the study could not assess whether there was an increase in the use of male contraceptive methods, particularly condoms. Because of resource constraints, training regarding NSV was not given. Condom distribution was not documented in this study. In a scale-up of this intervention, it is recommended that more attention should be given to assess the impact of the intervention on the use of male contraceptive methods, particularly condoms. 


\section{REFERENCES}

Asian-Pacific Resource and Research Centre for Women. 1996. "Men's Roles and Responsibilities in Reproduction," ARROWS for Change, Vol. 2 (1): 1-12.

Ashraf, A., T. T. Kane, A. Shahriar and B. Khuda. 1999. "Male Involvement in Reproductive Health Services in Bangladesh: A Review," special publication. Operations Research Project, Health and Population Extension Division. Dhaka: ICDDR,B.

Donahoe, Debbie. 1996. "Men and Family Planning in Bangladesh: A Review of the Literature," Dhaka: Population Council.

David, F. 1996. "Male Involvement in Family Planning." In the Proceedings of the Operations Research Training Workshop: Mainstreaming NFP in the Public Sector. Manila, Philippines.

Directorate of Family Planning, NIPORT and Population Council. 1998. "Getting Men Involved in Family Planning: Experience from an Innovative Program.” Asia \& Near East Operations Research and Technical Assistance Project Final Report. Dhaka, Bangladesh.

Hussain, M. A., G. S. Rahman and N. Begum. 1996. "A Study on Prevalence of RTI/STDs in a Rural Area of Bangladesh." Dhaka: Save the Children (USA).

Khan M.A., M. Rahman, P.A. Khanum, B.-Khuda, T.T.Kane, and A. Ashraf 1996. "Awareness of Sexually Transmitted Disease Among Women and Service Providers in Rural Bangladesh. Dhaka: MCH-FP Extension project (Rural)," Working Paper, 123; International Centre for Diarrhoeal Disease Research, Bangladesh.

Kim, Y. M., C. Marangwanda and A. Kols, 1996. "Involving Men in Family Planning: The Zimbabwe Male Motivation and Family Planning Method Expansion Project, 1993-1994," IEC Field Report No. 3., Baltimore: Johns Hopkins Bloomberg School of Public Health, Center for Communication Programs.

Mitra, S. N., M. N. Ali, S. Islam, A. R. Cross, and T. Saha. 1994. Bangladesh Demographic and Health Survey 1993-1994. Dhaka, Bangladesh: National Institute of Population Research and Training, Mitra and Associates and Calverton, Maryland: Macro International Inc.

NIPORT, Mitra and Associates, and ORC Macro. 2001. Bangladesh Demographic and Health Survey 1999-2001. Dhaka, Bangladesh: National Institute of Population Research and Training, Mitra and Associates and Calverton, Maryland: ORC Macro.

Piet-Pelon, N, U. Rob and M.E. Khan. 2000. Men in Bangladesh, India and Pakistan: Reproductive Health Issues. Dhaka: Karshaf Publishers. 
Piet-Pelon, N. and U. Rob. 1997. "Male Involvement in the Bangladesh Family Planning and Reproductive Health Program," International Quarterly of Community Health Education. Vol 17 (2):195-206.

Population Council. 1996a. "Male Involvement: A Challenge for the Bangladesh National Family Planning Program,” Policy Dialogue No. 2. Dhaka: Population Council.

Population Council. 1996b. "Integration of RTI Care into Existing Family Planning Services," Policy Dialogue No. 3. Dhaka: Population Council.

Population Council. 1997. "Male Involvement in Family planning: Experiences from Innovative Projects," Workshop on Male Involvement, Dhaka: Population Council.

Rob, U., S. M. I. Hossain, I. Bhuiya, A. Al Sabir and A. Alam. 2002. "Integration of Reproductive Health Services for Men in Family Welfare Centres," FRONTIERS Research Update No. 1. Dhaka: Population Council.

Wasserheit, J. N. et al. 1989. "Reproductive Tract Infection in a Family Planning Population in Rural Bangladesh," Studies in Family Planning 20(2): 69-79. 


\section{APPENDIX}

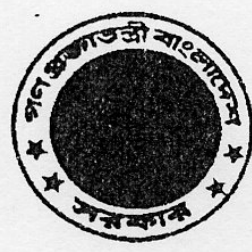

Secretary

Ministry of Health \& Family Welfare

Govt. of the People's Republic of Bangladesh

D.O.NO:MOHFW PrOg-2NIPORT-1102:282

Date:20-11-2002.

Dear Mr.Khan,

It is indeed a gre it pleasure for me to note that NIPORT has done a good deal of Operation R secarch activities on "Integration of Reproductive Health Services for Men " Union Health and Family Welfare Centres" and successfully held the lay long dissemination workshop on 24 October. 2002.

2. I would likic to the nk you as DG of NIPORT for this commendable job. It is expected that the econmendations of this workshop on operations research will be a new addition to the efforts for rejuvenating the Reproductive Health Services Programme. This is also likely to facilitate the access of men to reproductive health serices at union level senvice delivery points alongwith the ongoing government lemale focused RH care delivery system. At this point I would like to request you to upscale the Operations Research activities concerning 100-150" Union Health and Family Welfare Centres"

$$
\text { Wit Regaids }
$$

Mr. A.R.Khan,

Director General.

NIPORT.Azimpur

Dhaki.

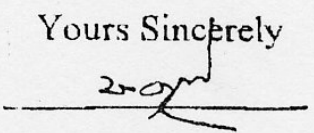

(1. Fazlur Rahman)
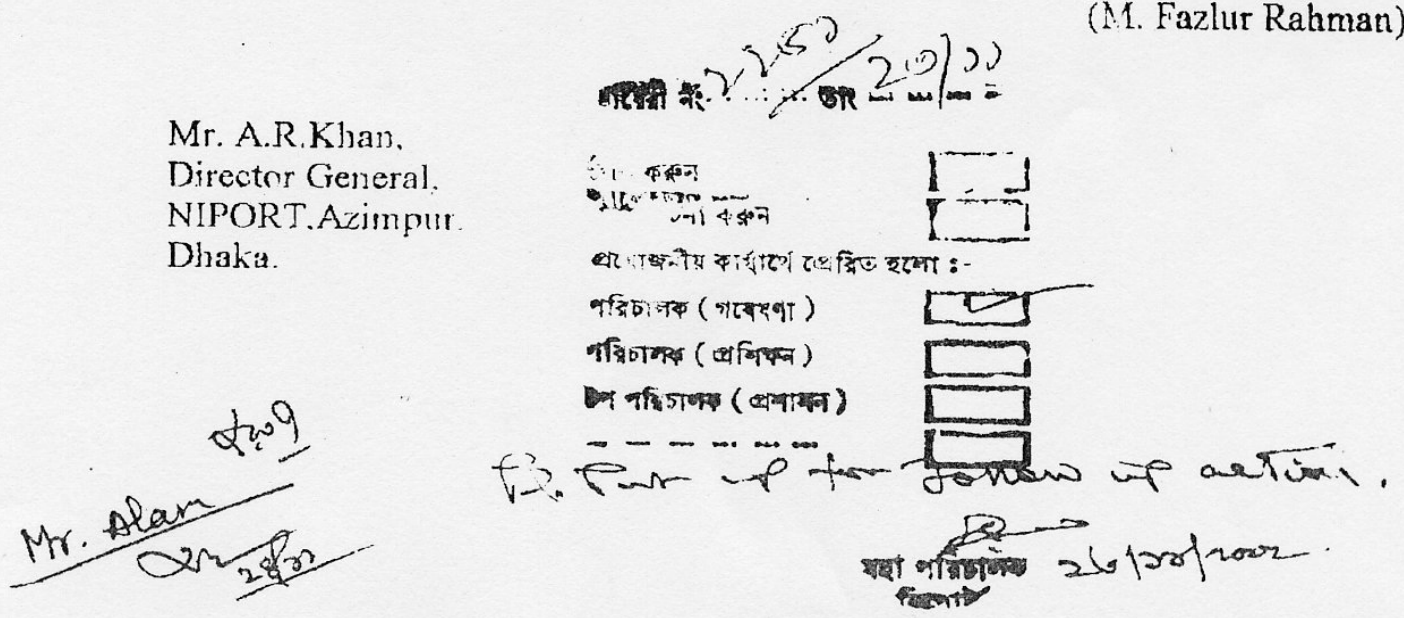

Integration of Reproductive Health Services for Men in HFWCs in Bangladesh in Bangladesh 